\title{
SINGLE FACTOR STOCHASTIC MODELS WITH SEASONALITY APPLIED TO UNDERLYING WEATHER DERIVATIVES VARIABLES*
}

\author{
Hipòlit Torró, Vicente Meneu and Enric Valor ${ }^{* *}$
}

WP-EC 2001-22

Correspondence to: Hipòlit Torró. Universitat de València. Facultat d'Economia. Av. dels Tarongers, s/n. 46071 Valencia (Spain). Tel.: +34963828392 / Fax: +34963828370 / email: hipolit.torro@uv.es

Editor: Instituto Valenciano de Investigaciones Económicas, S.A.

Primera Edición Noviembre 2001

Depósito Legal: V-4661-2001

IVIE working papers offer in advance the results of economic research under way in order to encourage a discussion process before sending them to scientific journals for their final publication.

\footnotetext{
* This paper is part of a research project being carried out with FC\&M, the Spanish commodity derivative exchange. Partial financial support was provided by the Institut Valencià d'Investigacions Econòmiques and the Fundación Caja de Madrid. The Instituto Nacional de Meteorología (INM) provided the data used in the study. We are also grateful for the comments and suggestions of A. Peiró, A. Pardo and J. Lucía. The usual caveat applies.

${ }^{* *}$ H. Torró and V. Meneu: Universitat de València (Departament d'Economia Financera i Matemàtica); E. Valor: Universitat de València (Departament de Termodinàmica).
} 


\title{
SINGLE FACTOR STOCHASTIC MODELS WITH SEASONALITY APPLIED TO UNDERLYING WEATHER DERIVATIVES VARIABLES
}

\author{
Hipòlit Torró, Vicente Meneu and Enric Valor
}

\begin{abstract}
A B S T R A C T
This paper estimates single factor stochastic models describing daily air temperature behaviour. We modify classical financial models to reflect temperature seasonality and fit them to a time series representing temperatures in Spain. The estimated models are used in Montecarlo simulations to obtain heating and cooling degree-days, which are used as an underlying reference in weather derivatives. The final goal of this work is to obtain an insight into weather derivative valuation, and so making it easier to manage economic activity risks closely related to temperature (i.e. oil, gas and electricity prices and volumes).
\end{abstract}

Keywords: Cooling Degree-days, Energy, Heating Degree-days, Seasonality, Stochastic Models, Weather Derivatives.

JEL Classification: G10-G12

\section{R E S U M E N}

En este trabajo se estiman modelos estocásticos unifactoriales que describen el comportamiento de la temperatura del aire de un índice representativo de la España peninsular. Los modelos más utilizados en finanzas se adaptan para incorporar el comportamiento estacional de la variable temperatura. El objetivo de este trabajo es obtener resultados que permitan avanzar en la valoración de activos derivados sobre climatología. Este tipo de derivados permiten gestionar riesgos de la actividad económica estrechamente relacionados con la temperatura (por ejemplo, los riesgos de precio y volumen del gas y la electricidad). Con los modelos estimados se realiza un ejercicio de simulación de Montecarlo para obtener los grados día frío y los grados día calor que son las referencias subyacentes en los contratos de meteorología.

Palabras clave: Grados Día Frío, Energía, Grados Día Calor, Estacionalidad, Modelos estocásticos y Derivados de la meteorología.

JEL Classification: G10-G12 


\section{Introduction}

In recent years, there has been a huge increase in the traded volume of derivatives with non-tradable underlying assets. These products, including catastrophic damage and weather derivatives, are different in some respects to traditional commodities. The study of the latter is the object of this paper.

Weather derivatives (forward, futures and option contracts) depend on the evolution of a meteorological variable: temperature, wind speed, rainfall, etc. These contracts are attractive in many economic activities whose outcomes depend on these phenomena. Some examples include the power production of windmill park depending on wind speed, and power production in Norway depending on rainfall and snowfall, since 98 per cent of power is produced by water resources. These kind of derivatives can be used to manage both price and volume risks.

The relationship between weather variables and electricity load and price has been studied in the literature by many authors. Weather variables considered in these studies are temperature, wind speed, humidity and precipitation. Li and Sailor (1995), and Sailor and Muñoz (1998), find in a sample of US states that temperature is the most significant weather factor explaining electricity and gas demand. The influence of air temperature in electricity demand and price has been considered by other authors, who obtained a significant explicative power in their modelling see, for example, Peirson and Henley (1994), Henley and Peirson (1998), Engle et al. (1992), and Pardo et al. (2000). Figure 1 shows the relationship between electricity load and air temperature observed in Spain. The dependence of power demand on temperature is significant, and the relation is non-linear, showing an increasing electricity demand both for decreasing and increasing temperatures, corresponding to winter (use of heating appliances) and summer (use of air conditioning), respectively.

Traders and financial entity analyst departments that offer weather derivatives overthe-counter, or in organised markets ${ }^{1}$, try to price these contracts using their experience in other commodities. As a result, they apply their financial background to describe commodity price behaviour. However, weather variables have not been practically modelled in the literature ${ }^{2}$.

\footnotetext{
${ }^{1}$ The Chicago Mercantile Exchange lists derivatives on the monthly accumulated heating and cooling degreedays above or below a critical level. This is calculated with data from a set of American cities. See CME Web site for more details on these futures and option contracts (http://www.cme.com). In Europe, Eurex has wheather derivatives into its planned products (http://www.eurexchange.com).

${ }^{2}$ Dischel (1998) presents a bifactorial stochastic model with mean reversion.
} 
Figure 1: Relationship between electricity load and temperature in Spain for year 1997.

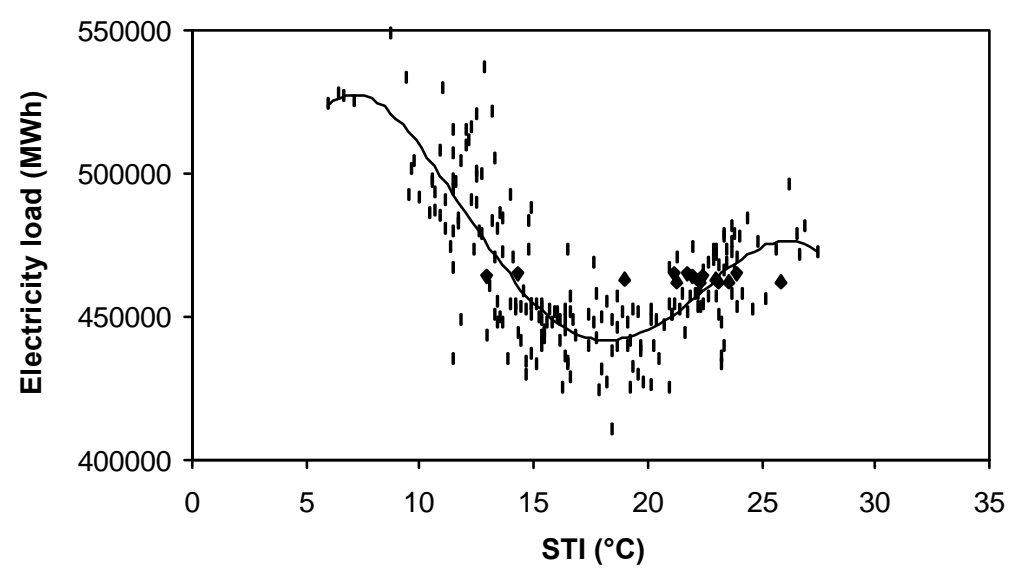

Weather variables are not tradable, and that is why the classical Black-Scholes methodology cannot be applied directly as it cannot hedge derivative contracts, and the temperature market price of risk is unknown. Alternatively, a Montecarlo simulation can be used to find stochastic models that better replicate the underlying weather variable behaviour and derivative payoffs. This is the only course of action possible with these variables because risk-neutral valuation cannot be applied until some asset depending on weather (bonds, forwards, futures, options) begins to be traded in significant volumes.

In this paper, we develop a daily air temperature index for Spain (Spanish Temperature Index, STI henceforth) as a population-weighted average of the air temperatures observed in four weather stations located in Bilbao (northern Spain), Madrid (central Spain), Seville (southern Spain) and Valencia (eastern Spain). The data was reported by the Instituto Nacional de Meteorología for the period January 1970 to April 1999. The objective of the paper is to model the behaviour of STI by using a single factor stochastic model that should capture the basic characteristics of this variable.

Power in Spain is traded in a mandatory pool with a single hourly price for the whole continental territory (islands are not included). This is why we compute the STI within the same geographical zone. The explicative capability of STI over electricity load (see Figure 1) is an important reason for studying STI behaviour as a clear candidate for underlying reference in derivatives contracts. A similar situation is expected for the gas market in the near future. 
This paper is organised as follows. In the second section, we study the statistical patterns defining temperature behaviour in an attempt to discover which financial assets share the most similarities. Then it will be possible to apply a financial asset modelling background. We conclude that interest rate models are quite suitable but seasonal adjustments must be incorporated.

In section 3, we propose a general model containing the basic features of temperature behaviour. This model can be restricted to obtain the classical continuous single factor interest rate models. In section 4 , we estimate a set of ten models to find which best describes temperature behaviour and test nesting restrictions. In section 5, estimated models are used to simulate derivative payoffs. Finally, the main conclusions are collected in section 6 .

Results are interesting for two reasons. Firstly, for the wide range of estimated models allowing the identification of seasonal patterns, mean reversion, autoregressive structures in conditional volatilities; as well as relationships between volatility and temperature levels. Secondly, for its inner interest for the economical agents involved with the consequences of unexpected weather behaviour.

\section{Preliminary Analysis}

The purpose of this section is to study the basic statistical features of the daily STI series, in order to discover if temperature behaves in a similar way to a well-known financial variable; and if it is sensible to use the same models and how to adapt them. Which statistical features are important in financial modelling? Basically, asset prices, interest rates, foreign currencies exchange rates, are not usually allowed to take negative values and they have a high autocorrelation, mean reversion and autocorrelated heteroskedasticity.

Firstly, it is quite remarkable that STI shows a significant seasonal behaviour that is not shown by financial variables and this can be easily seen in Figure 2. This figure shows the evolution of the STI within the sample data corresponding to the period [1-1-1970; 30-41999] with 10712 daily observations. A strong seasonal behaviour with an annual period can be seen, and this should be taken into account in any model. Figure 3 exhibits the histogram for the data series, where a bimodal distribution can be observed corresponding to the different year seasons (the histograms with the year split into two seasons: winter and summer, are also plotted in Figure 3). We will use this basic feature extending the classical financial modelling to capture weather seasonality in the following section. 
Figure 2: Daily evolution of the Spanish Temperature Index for the period [1-1-1970; 30-4-1999]

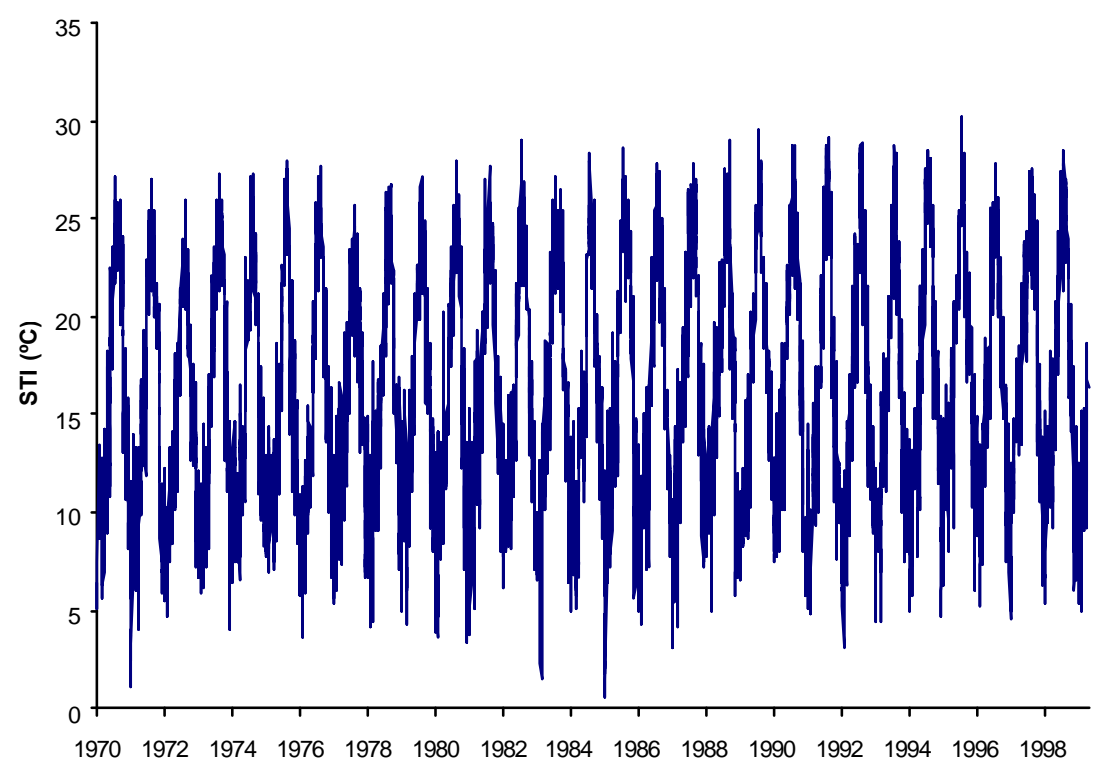

Figure 3: Histogram for the sample data for the period [1-1-1970; 30-4-1999] with 10712 daily observations

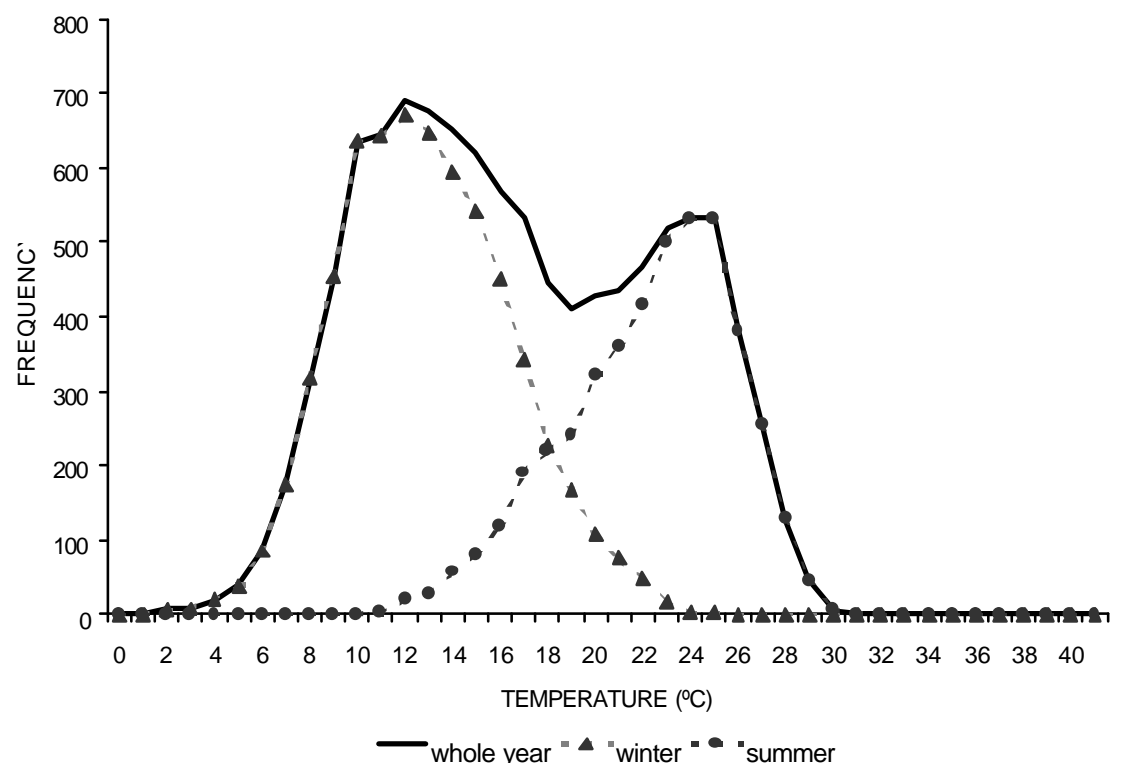


The STI series does not show negative values (see Table I), as we are analysing the temperature of a warm country. In a general sense, it can be said that the variable temperature is constrained within two physical limits, which depend on the temperature scale used. In this work, we are using the Celsius scale, and in our sample, the STI does not take negative values, so it will not be a strong restriction if the model we obtain does not allow the variable to take negative values.

Table I: Data Description and Statistics

\begin{tabular}{|c|c|c|c|c|c|c|c|}
\hline \multirow{3}{*}{$\begin{array}{l}\text { STI } \\
\text { Sample } \\
\text { Series } \\
\text { Units }\end{array}$} & \multicolumn{7}{|c|}{$\begin{array}{l}\text { Source: Instituto Nacional de Meteorología (Spain) } \\
\text { Population-weighted average of mean daily temperatures measured at four weather } \\
\text { stations } \\
\text { From January } 1^{\text {st }}, 1970 \text { to April } 30^{\text {th }}, 1999\end{array}$} \\
\hline & \multicolumn{7}{|c|}{10712 observations } \\
\hline & \multicolumn{7}{|l|}{ Celsius degrees } \\
\hline & Mean & Max & Min & Std. Dev. & Skewness & Kurtosis & Bera-Jarque \\
\hline $\mathbf{S T I}_{t}$ & 16.27 & 30.20 & 0.59 & 5.87 & $0.14 *$ & $1.95^{*}$ & $525.65^{*}$ \\
\hline $\log \mathrm{STI}_{\mathrm{t}}$ & 2.72 & 3.41 & -0.53 & 0.40 & $-0.68^{*}$ & $3.84 *$ & $820.83 *$ \\
\hline $\log S T I_{t} / S_{T I}$ & $8.50 \cdot 10^{-5}$ & 1.50 & -1.43 & 0.11 & $0.28 *$ & $15.31 *$ & $67735^{*}$ \\
\hline
\end{tabular}

*Tested hypothesis is rejected with a $1 \%$ significance level.

Skewness means the skewness coefficient and has the asymptotic distribution $\mathrm{N}(0 ; 6 / \mathrm{T})$, where $\mathrm{T}$ is the sample size. The null hypothesis tested is the skewness coefficient is equal to zero. Kurtosis means the kurtosis coefficient and it has an asymptotic distribution of $\mathrm{N}(3,24 / \mathrm{T})$. The hypothesis tested is kurtosis coefficient is equal to zero. The Bera-Jarque statistic tests the normal distribution hypothesis. The Bera-Jarque statistic is calculated as Bera-Jarque $=\mathrm{T}[$ Skewness $2 / 6+($ Kurtosis-3 $) 2 / 24]$. The BeraJarque statistic has an asymptotic $\chi_{2}^{2}$ distribution under the normal distribution hypothesis.

The STI series has a strong autocorrelation, as can be deduced from Table II, which shows the first ten autocorrelation coefficients. It is quite clear that changes in temperature have a long memory. The autocorrelation coefficients are very close to one and significantly different from zero.

Mean reversion is another feature that the STI series clearly displays. This means that changes never allow STI levels to go too far from a long run equilibrium value. Table III displays the first ten autocorrelation coefficients for the differenced STI series, where nine out of ten have negative value, all of which are significantly different from zero and decline dramatically. This behaviour can be understood because deviations from the seasonal trend tend to disappear in a few days. 


\section{Table II: Autocorrelation Coefficients for the STI Series}

Autocorrelation coefficients of order $\mathrm{j}$ are represented by $\rho_{\mathrm{j}}$ for the Spanish Temperature Index (STI), $\mathrm{I}_{\mathrm{t}}$. p-value means the critical significance level for the Ljung-Box statistic $\mathrm{Q}$ testing the null hypothesis of zero autocorrelation coefficients until order $\mathrm{j}$.

\begin{tabular}{ccccccccccc}
\hline & $\rho_{1}$ & $\rho_{2}$ & $\rho_{3}$ & $\rho_{4}$ & $\rho_{5}$ & $\rho_{6}$ & $\rho_{7}$ & $\rho_{8}$ & $\rho_{9}$ & $\rho_{10}$ \\
\hline Coefficient & 0.975 & 0.945 & 0.923 & 0.908 & 0.896 & 0.886 & 0.878 & 0.871 & 0.864 & 0.859 \\
p-value & 0.000 & 0.000 & 0.000 & 0.000 & 0.000 & 0.000 & 0.000 & 0.000 & 0.000 & 0.000 \\
\hline
\end{tabular}

Table III: Autocorrelation Coefficients for $\Delta$ STI Series

Autocorrelation coefficients of order $\mathrm{j}$ are represented by $\rho_{\mathrm{j}}$ for the differenced Spanish Temperature Index (STI), $\mathrm{I}_{\mathrm{t}}$. p-value means the critical significance level for the Ljung-Box statistic Q testing the null hypothesis of zero autocorrelation coefficients until order $\mathrm{j}$.

\begin{tabular}{ccccccccccc}
\hline & $\rho_{1}$ & $\rho_{2}$ & $\rho_{3}$ & $\rho_{4}$ & $\rho_{5}$ & $\rho_{6}$ & $\rho_{7}$ & $\rho_{8}$ & $\rho_{9}$ & $\rho_{10}$ \\
\hline Coefficient & 0.119 & -0.168 & -0.138 & -0.068 & -0.041 & -0.026 & -0.030 & -0.009 & -0.017 & -0.011 \\
p-value & 0.000 & 0.000 & 0.000 & 0.000 & 0.000 & 0.000 & 0.000 & 0.000 & 0.000 & 0.000 \\
\hline
\end{tabular}

It is very common in asset modelling to find that underlying variable levels help explain their own volatility. In Table IV we present the linear regression between the STI conditioned volatility and the STI level. It is interesting to stress that the coefficient we obtain for the lagged temperature is quite small but statistically significant. A possible meaning of this small coefficient is that the temperature level will not greatly help explain its volatility. Another way to explain volatility is by using Generalised Autoregressive Conditional Heteroskedastic models (see Engle (1982) and Bollerslev (1986)). From Table V we deduce that conditioned volatility (squared differenced STI series) behaviour fits very well in GARCH models. The general behaviour model we use in the next section simultaneously reflects both effects.

From the results obtained in this preliminary analysis, it is admissible to fit stochastic models to the STI, in the same way as financial doctrine does with other variables. However, we also include the observed seasonal pattern. We will pay special attention to some interest rate stochastic models incorporating mean reversion, heteroskedasticity and high autocorrelation. In the next section, a collection of stochastic models is fitted to daily air temperature data. 


\section{Table IV: Linear Regression between STI Conditioned}

Volatility and STI Level

The squared standardised temperature is used as a proxy for measuring volatility.

The coefficients are estimated by ordinary least squares in the linear relationship

$$
\left(\frac{\mathrm{STI}_{\mathrm{t}}-\overline{\mathrm{STI}}}{\sigma_{\mathrm{STI}}}\right)^{2}=\alpha+\beta \mathrm{STI}_{\mathrm{t}-1}+\varepsilon_{\mathrm{t}}
$$

$\mathrm{R}^{2}$ is the regression determination coefficient, No. Obs. is the number of observations into the period [1-1-1970; 30-4-1999].

\begin{tabular}{ccccc}
\hline & $\alpha$ & $\beta$ & $\mathrm{R}^{2}$ & $\mathrm{~N}^{\mathrm{o}}$ Obs. \\
\hline Coefficient & 0.5684 & 0.0264 & 0.02576 & 10712 \\
t-Student & 20.70 & 16.64 & & \\
\hline
\end{tabular}

\section{Table V: Heteroskedasticity Tests}

$\mathrm{Q}^{2}$ represents the Ljung-Box statistic testing the null hypothesis of zero autocorrelation coefficients in squared differenced STI series, $(\Delta \mathrm{STI})^{2}$. Under the null hypothesis, the statistic has an asymptotic distribution $\chi^{2}$ with degrees of freedom equal to the number of lags in the test. The Engle (1982) test for heteroskedasticity is also displayed.

\begin{tabular}{cccc}
\hline No. of lags & Ljung-Box $\mathbf{Q}^{\mathbf{2}}$ & Engle Test & ${\boldsymbol{\boldsymbol { \chi } _ { ( 0 . 0 1 ) } ^ { \mathbf { 2 } }}}$ \\
\hline 10 & 221.19 & 169.30 & 23.2 \\
20 & 238.36 & 181.26 & 37.6 \\
36 & 269.79 & 201.46 & 58.6 \\
\hline
\end{tabular}

\section{Methodology}

This work follows the approach pioneered by Chan, Karoly, Longstaff and Sanders (1992) (referred to as CKLS). CKLS estimate and compare a set of classical continuous time single factor equilibrium stochastic models describing short term interest rates behaviour, including Vasicek (1977), Cox, Ingersoll and Ross (1985) (CIR (85) from now on) and Brennan and Schwartz (1982) (referred to as BS). These models use a constant mean reversion structure, and some consider the influence of the variable level on volatility. 
Bali (1999) proposes a more general model than CKLS. He adds a GARCH behaviour in the volatility parameters allowing simultaneous volatility to depend on interest rate levels. In the model proposed by Bali, all the other models are nested and can be obtained under certain parameter restrictions. The model we propose captures volatility through the GARCH structure and through the variable level.

A seasonal trend term has been introduced to account for the strong seasonality shown by temperature. Seasonal patterns have been observed by other authors in modelling energy prices (Pilipovic (1998, p. 67)), and valuing power demand and derivatives (Pirrong and Jermakyan (1999, p. 61)). Following these authors, we introduce a similar seasonal trend.

Taking into account these considerations, the model that we propose for temperature modelling is displayed in the following stochastic differential equation ${ }^{3}$

$$
\mathrm{dI}_{\mathrm{t}}=\left[\alpha_{0}+\alpha_{1} \mathrm{I}_{\mathrm{t}}+\alpha_{2} \cos \left(\alpha_{3} \theta(\mathrm{t})+\alpha_{4}\right)\right] \mathrm{dt}+\Psi_{\mathrm{t}} \mathrm{I}_{\mathrm{t}}^{\gamma} \mathrm{dW}
$$

where $I_{t}$ is STI, $\theta(t)=2 \pi t / 365$ ( $t$ given in days) considering an annual period; $d W_{t}$ is a standard Brownian motion; $\Psi_{\mathrm{t}}$ is the scale factor changing over time and represents structural changes in the volatility, and depends on unexpected shocks in temperature.

It is important to note that the trend is specified by $\alpha_{0}+\alpha_{1} I_{t}+\alpha_{2} \cos \left(\alpha_{3} \theta(t)+\alpha_{4}\right)$. In this way, the model introduces reversion to a time-dependent value varying seasonally, instead of reverting to a constant value. The time-dependent function represents the seasonal trend shown by temperature, which resembles a harmonic function - and this is the reason why the cosine function is introduced into the model. The coefficients of this function are related to its amplitude $\left(\alpha_{2}\right)$, its time frequency $\left(\alpha_{3}\right)$, and the phase $\left(\alpha_{4}\right)$, respectively.

The discrete time approximation to (1) is

$$
\begin{gathered}
\Delta \mathrm{I}_{\mathrm{t}}=\left[\alpha_{0}+\alpha_{1} \mathrm{I}_{\mathrm{t}}+\alpha_{2} \cos \left(\alpha_{3} \theta(\mathrm{t})+\alpha_{4}\right)\right] \Delta \mathrm{t}+\Psi_{\mathrm{t}+\Delta \mathrm{t}} \mathrm{I}_{\mathrm{t}}^{\gamma} \Delta \mathrm{W}_{\mathrm{t}} \\
\Delta \mathrm{W}_{\mathrm{t}}=\varepsilon_{\mathrm{t}+\Delta \mathrm{t}} \sqrt{\Delta \mathrm{t}}, \Psi_{\mathrm{t}+\Delta \mathrm{t}}^{2}=\beta_{0}+\beta_{1} \varepsilon_{\mathrm{t}}^{2}+\beta_{2} \Psi_{\mathrm{t}}^{2}
\end{gathered}
$$

\footnotetext{
${ }^{3}$ In Bali (1999) the coefficients are defined to be time-varying in a rolling regression procedure, which is very useful when the objective is to compare models in a dynamic environment. This is quite suitable for interest rate analysis, although it is unnecessary to model temperature because structural changes would mean the implausible hypothesis of often-dramatic climatic changes.
} 
where $\Delta \mathrm{t}$ is the time interval length; $\Delta \mathrm{I}_{\mathrm{t}}=\mathrm{I}_{\mathrm{t}+\Delta \mathrm{t}}-\mathrm{I}_{\mathrm{t}}$ is the variation in the STI; $\varepsilon_{\mathrm{t}+\Delta \mathrm{t}}$ represents unexpected shocks in temperature, which is a random drawing from a standardised normal distribution with zero mean and unitary variance. $\Delta \mathrm{W}_{\mathrm{t}}$ has a normal distribution with $\Delta \mathrm{t}$ variance. $\Psi_{\mathrm{t}+\Delta \mathrm{t}}$ is an autoregressive function of $\varepsilon_{\mathrm{t}}$ in a $\operatorname{GARCH}(1,1)$ structure. Nine parameters are estimated: $\alpha_{0}, \alpha_{1}, \alpha_{2}, \alpha_{3}, \alpha_{4}, \beta_{0}, \beta_{1}, \beta_{2}$ and $\gamma$.

The conditional variance term in equation (1) is given by $\Psi_{\mathrm{t}}^{2} \mathrm{I}_{\mathrm{t}}{ }^{2 \gamma}$. This term has the property of collecting a GARCH structure (see equation (2)) and the temperature level as a set in the same model describing the conditional volatility behaviour.

From the general equation (1), many models can be obtained by imposing different restrictions on the parameters. However, we have only focused on those models that include a mean reversion structure, adding in all cases the harmonic term to account for seasonality ${ }^{4}$. These models are nested in the general model, so constraining restrictions can be tested. The general process, and all other processes, are derived from the restrictions collected in Table VI. Models VASICEK, CIR(85), and BS are widely used as stochastic processes for interest rates. In addition, they have the advantage of providing closed formulae for the valuation of derivatives. Models SVASICEK, SCIR(85), and SBS are each one of these models, respectively, with an added seasonal term.

Table VI: Parameter Restrictions Imposed by Alternative Models

$$
\begin{aligned}
& I_{t+\Delta t}-I_{t}=\alpha_{0}+\alpha_{1} I_{t}+\alpha_{2} \cos \left(\alpha_{3} \theta(t)+\alpha_{4}\right)+\varepsilon_{t} \\
& \sigma_{t+\Delta t}^{2}=\Psi_{t+\Delta t}^{2} I_{t}^{2 \gamma}, \quad \Psi_{t+\Delta t}^{2}=\beta_{0}+\beta_{1} \varepsilon_{t}^{2}+\beta_{2} \Psi_{t}^{2}
\end{aligned}
$$

The specifications displayed are: (1) and (6) see equation (1); (2) and (7) see Chan et al. (1992); (3) and (8) see Vasicek (1977); (4) and (9) see Cox et al. (1985); (5) and (10) see

\begin{tabular}{|c|c|c|c|c|c|c|c|c|c|c|}
\hline & MODEL & $\alpha_{0}$ & $\alpha_{1}$ & $\alpha_{2}$ & $\alpha_{3}$ & $\alpha_{4}$ & $\beta_{0}$ & $\beta_{1}$ & $\beta_{2}$ & $\gamma$ \\
\hline \multirow[t]{4}{*}{ Seasonality } & $\begin{array}{ll}\text { (1) SGENERAL } \\
\text { (2) SCKLS }\end{array}$ & & & & & & & 0 & 0 & \\
\hline & (3) SVASICEK & & & & & & & 0 & 0 & 0 \\
\hline & (4) $\operatorname{SCIR}(85)$ & & & & & & & 0 & 0 & 0.5 \\
\hline & (5) SBS & & & & & & & 0 & 0 & 1 \\
\hline \multirow{5}{*}{ No seasonality } & (6) GENERAL & & & 0 & 0 & 0 & & & & \\
\hline & (7) CKLS & & & 0 & 0 & 0 & & 0 & 0 & \\
\hline & (8) VASICEK & & & 0 & 0 & 0 & & 0 & 0 & 0 \\
\hline & (9) CIR(85) & & & 0 & 0 & 0 & & 0 & 0 & 0.5 \\
\hline & (10) BS & & & 0 & 0 & 0 & & 0 & 0 & 1 \\
\hline
\end{tabular}
Brennan and Schwartz (1982).

\footnotetext{
${ }^{4}$ We have also estimated other models that do not use mean reversion, but the obtained results are not meaningful despite the fact that the seasonal term has been considered.
} 


\section{The Empirical Results}

The general model and its nested models have been estimated maximising the loglikelihood function using the Berndt et al. (1974) algorithm ${ }^{5}$. The advantage of using a normal probability distribution in the estimation methodology is that this allows an easy application of binomial tree approximation from discrete time to continuous time probability distribution.

Table VII presents the estimation results. The most significant models are (in decreasing order): (1) SGENERAL, (2) SCKLS and (3) SVASICEK. The others, SCIR(85) and SBS, show quite poor results. For comparison purposes, the last five rows in Table VII show the results for these models but without seasonality. If a seasonal trend is not included, the ranking through the models remains the same.

Models with free $\gamma$ or $\gamma=0$ are clearly the best. When $\gamma$ is free its value is always close to zero and negative. This can be understood as temperature level and its volatility have an opposite relationship. That is, temperature is more volatile when it is low, and is less volatile in warm seasons. This fact can be appreciated in Figure 4. The conditional volatilities in the SGENERAL model achieve their highest values in cool seasons and the lowest values in warm seasons. ${ }^{6}$

The mean reversion is present in the models when $\alpha_{1}$ is below zero. This feature is clear in all the models. The likelihood of the seasonal effect becomes clear, since the parameters $\alpha_{2}, \alpha_{3}$ and $\alpha_{4}$ have significant values in seasonal models (1) to (5). The null hypothesis of no seasonal effect is clearly rejected.

\footnotetext{
5 Similar models applied to interest rates are estimated using maximum likelihood (Brenner et al. 1996, Bali 1999).

${ }^{6}$ Some empirical works on interest rates have shown that models with estimated $\gamma$ above 1.5 have more explicative power when monthly data is used (Chan et al. (1992)). Moreno and Peña (1996) show that models with $\gamma$ close to, but below 1.0, fit better with daily data. Therefore, in the empirical application to interest rates, it seems that $\gamma$ decreases when data frequency increases. We use daily temperature data in our application, but it would be interesting to compare parameters values with different data frequency.
} 
Table VII: In-Sample Estimates and Comparisons with the Nested Models in the General Model

This table displays the parameter estimates with asymptotic t-statistics in parentheses for each model. The maximised log-likelihood for the general model and for each nested models is shown. The likelihood ratio (LR) test statistics with associated degrees of freedom (df) and the associated Chi-Squared critical values $\chi_{(0.01)}^{2}$ at a $1 \%$ level of significance are reported. The parameters are estimated from the discrete time system of equations in expression (2) in the text.

\begin{tabular}{|c|c|c|c|c|c|c|c|c|c|c|c|c|c|c|c|}
\hline MODELS & & & $\alpha_{0}$ & $\alpha_{1}$ & $\alpha_{2}$ & $\alpha_{3}$ & $\alpha_{4}$ & $\beta_{0}$ & $\beta_{1}$ & $\beta_{2}$ & $\gamma$ & Log-likelihood & LR & $\chi_{(0.01)}^{2}$ & $\mathrm{df}$ \\
\hline \multirow[t]{5}{*}{ Seasonality } & (1) & SGENERAL & $\begin{array}{l}3.4082 \\
(17.00)\end{array}$ & $\begin{array}{c}-0.4287 \\
(-9.64)\end{array}$ & $\begin{array}{l}1.0427 \\
(25.24)\end{array}$ & $\begin{array}{c}0.9999 \\
(3466.75)\end{array}$ & $\begin{array}{l}2.7273 \\
(86.88)\end{array}$ & $\begin{array}{l}1.2643 \\
(5.52)\end{array}$ & $\begin{array}{c}0.2345 \\
(6.92)\end{array}$ & $\begin{array}{l}0.6016 \\
(12.73)\end{array}$ & $\begin{array}{l}-0.1818 \\
(-10.69)\end{array}$ & -7508.77 & - & - & - \\
\hline & (2) & SCKLS & $\begin{array}{l}2.2252 \\
(26.82)\end{array}$ & $\begin{array}{l}-0.1365 \\
(-27.64)\end{array}$ & $\begin{array}{l}1.0543 \\
(26.25)\end{array}$ & $\begin{array}{c}0.9997 \\
(3375.79\end{array}$ & $\begin{array}{l}2.7421 \\
(86.87)\end{array}$ & $\begin{array}{l}5.6138 \\
(11.81)\end{array}$ & 0.0 & 0.0 & $\begin{array}{l}-0.2405 \\
(-15.44)\end{array}$ & -7598.09 & 178.64 & 9.21 & 2 \\
\hline & (3) & SVASICEK & $\begin{array}{l}2.2443 \\
(28.18)\end{array}$ & $\begin{array}{l}-0.1375 \\
(-28.32)\end{array}$ & $\begin{array}{l}1.0401 \\
(26.07)\end{array}$ & $\begin{array}{c}0.9998 \\
(3262.93)\end{array}$ & $\begin{array}{l}2.7486 \\
(85.41)\end{array}$ & $\begin{array}{l}1.5471 \\
(86.14)\end{array}$ & 0.0 & 0.0 & 0.0 & -7692.76 & 367.98 & 11.34 & 3 \\
\hline & (4) & $\operatorname{SCIR}(85)$ & $\begin{array}{l}2.2837 \\
(40.65)\end{array}$ & $\begin{array}{l}-0.1399 \\
(-39.21)\end{array}$ & $\begin{array}{l}1.0128 \\
(27.98)\end{array}$ & $\begin{array}{c}0.9998 \\
(3053.84)\end{array}$ & $\begin{array}{l}2.7700 \\
(83.71)\end{array}$ & $\begin{array}{c}0.1208 \\
(110.19)\end{array}$ & 0.0 & 0.0 & 0.5 & -8580.77 & 2144 & 11.34 & 3 \\
\hline & $(5)$ & SBS & $\begin{array}{l}2.2913 \\
(54.23)\end{array}$ & $\begin{array}{l}-0.1412 \\
(-64.54)\end{array}$ & $\begin{array}{l}0.9747 \\
(24.81)\end{array}$ & $\begin{array}{c}0.9997 \\
(3077.00)\end{array}$ & $\begin{array}{l}2.7996 \\
(97.06)\end{array}$ & $\begin{array}{c}0.0121 \\
(268.10)\end{array}$ & 0.0 & 0.0 & 1 & -10815.88 & 6614.22 & 11.34 & 3 \\
\hline \multirow[t]{5}{*}{ No seasonality } & (6) & GENERAL & $\begin{array}{c}0.3470 \\
(9.39)\end{array}$ & $\begin{array}{l}-0.0213 \\
(-10.38)\end{array}$ & 0.0 & 0.0 & 0.0 & $\begin{array}{l}1.0161 \\
(5.63)\end{array}$ & $\begin{array}{l}0.2083 \\
(7.28)\end{array}$ & $\begin{array}{l}0.6582 \\
(16.62)\end{array}$ & $\begin{array}{l}-0.1643 \\
(-10.03)\end{array}$ & -7871.40 & 725.56 & 11.34 & 3 \\
\hline & (7) & CKLS & $\begin{array}{l}0.0346 \\
(8.83)\end{array}$ & $\begin{array}{c}-0.0215 \\
(-9.86)\end{array}$ & 0.0 & 0.0 & 0.0 & $\begin{array}{l}5.6523 \\
(11.85)\end{array}$ & 0.0 & 0.0 & $\begin{array}{l}-0.2297 \\
(-14.81)\end{array}$ & -7988.80 & 960.06 & 15.09 & 5 \\
\hline & (8) & VASICEK & $\begin{array}{l}0.3980 \\
(11.04)\end{array}$ & $\begin{array}{l}-0.0244 \\
(-10.89)\end{array}$ & 0.0 & 0.0 & 0.0 & $\begin{array}{c}1.6492 \\
(86.09)\end{array}$ & 0.0 & 0.0 & 0.0 & -8034.84 & 1052.14 & 16.81 & 6 \\
\hline & (9) & $\mathrm{CIR}(85)$ & $\begin{array}{l}0.5751 \\
(22.46)\end{array}$ & $\begin{array}{l}-0.0353 \\
(-16.03)\end{array}$ & 0.0 & 0.0 & 0.0 & $\begin{array}{c}0.1217 \\
(106.79)\end{array}$ & 0.0 & 0.0 & 0.5 & -8898.46 & 2779.38 & 16.81 & 6 \\
\hline & (10) & $\mathrm{BS}$ & $\begin{array}{l}0.9088 \\
(98.25)\end{array}$ & $\begin{array}{c}-0.0594 \\
(36.19)\end{array}$ & 0.0 & 0.0 & 0.0 & $\begin{array}{c}0.0127 \\
(246.13)\end{array}$ & 0.0 & 0.0 & 1.0 & -11094.47 & 7171.40 & 16.81 & 6 \\
\hline
\end{tabular}




\section{Figure 4: Temperature changes and estimated general model with seasonality conditional} standard deviation within the first thousand observations (observation 1 corresponds to January $1^{\text {st }}$ ).

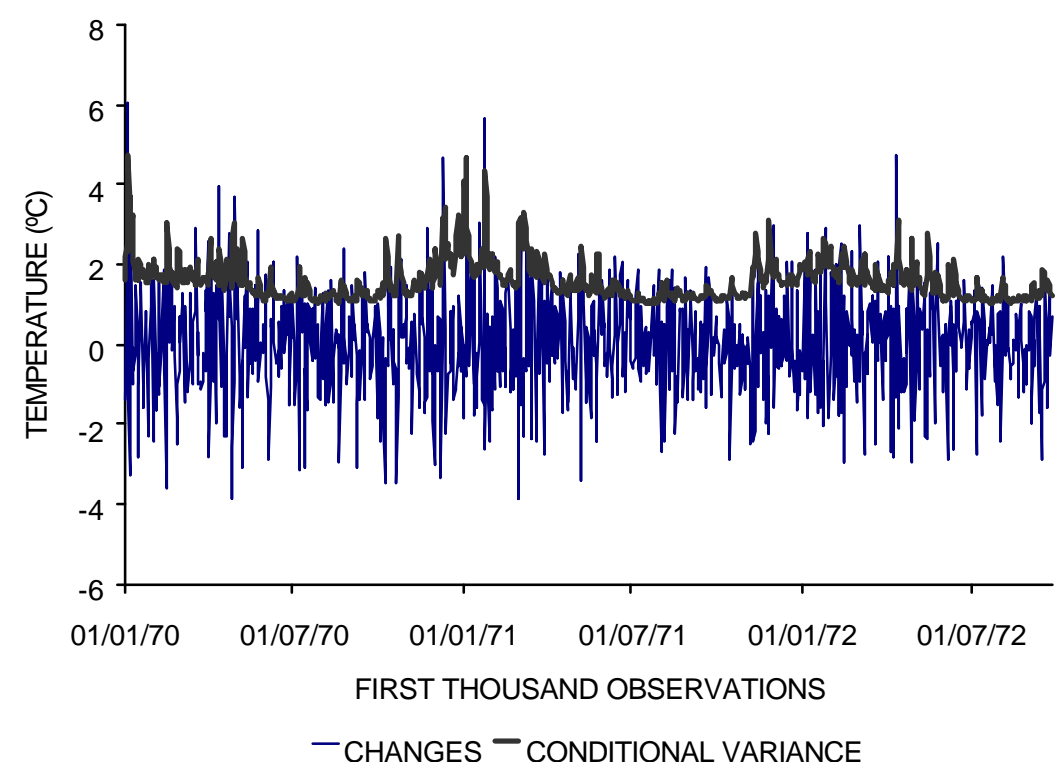

To further measure the relative performance of the nested models against the general model, we tested their predictive power for temperature change and conditional volatility. This is achieved by first computing the time series of conditional mean and conditional variance of the daily temperature changes for each model using the fitted values. Temperature change and variance ex post measures are obtained from the temperature series calculating $\left(\mathrm{I}_{\mathrm{t}}-\mathrm{I}_{\mathrm{t}-1}\right)$ and $\left(\mathrm{I}_{\mathrm{t}}-\mathrm{I}_{\mathrm{t}-1}\right)^{2}$.

Then we compute the Mean Square Error, MSE henceforth, for the forecasted conditional temperature changes, $\mathrm{MSE}_{\mathrm{C}}$, and for the forecasted conditional volatility, $\mathrm{MSE}_{\mathrm{V}}$. The lower the MSE of a model, the better its forecasting permormance. So, the MSE is a performance measure of how estimated models are able to forecast unexpected temperature change and conditional volatility. MSE is defined as follows

$$
\operatorname{MSE}=\frac{1}{\mathrm{~N}} \sum_{\mathrm{i}=1}^{\mathrm{N}}\left(\mathrm{y}_{\mathrm{i}}-\hat{y}_{\mathrm{i}}\right)^{2}
$$

where $\mathrm{y}_{\mathrm{i}}$ denotes the actual values of $\left(\mathrm{I}_{\mathrm{t}}-\mathrm{I}_{\mathrm{t}-1}\right)$ or $\left(\mathrm{I}_{\mathrm{t}}-\mathrm{I}_{\mathrm{t}-1}\right)^{2}$ and $\hat{\mathrm{y}}_{\mathrm{i}}$ the forecasted conditional temperature changes or the forecasted conditional variance in each model. From MSE values, 
see Table VIII, we obtain the same model preference than comparing loglikelihood function value in Table VII. But in order to obtain some more insight about the significance of MSE differences we have computed the Diebold and Mariano (1995) statistic $\mathrm{S}_{1}$. Using square errors as loss function the Diebold and Mariano test for the equivalence of forecast errors will be

$$
\mathrm{S}_{1}=\frac{\frac{1}{\mathrm{~T}} \sum_{\mathrm{t}=1}^{\mathrm{T}}\left[\left(\mathrm{e}_{\mathrm{it}}\right)^{2}-\left(\mathrm{e}_{\mathrm{jt}}\right)^{2}\right]}{\sqrt{\frac{2 \pi f(0)}{\mathrm{T}}}}
$$

where $e_{i}=y_{i}-\hat{y}_{i}$ and $e_{j}=y_{j}-\hat{y}_{j}$ are the forecast error for observation $t$ in two alternative models $\mathrm{i}$ and $\mathrm{j}, \mathrm{T}$ is the sample size and $f(0)$ is the spectral density of the difference of the square prediction errors at frequency zero. Diebold and Mariano show that $S_{1}$ is asymptotically distributed $^{7}$ as a $\mathrm{N}(0,1)$. As forecasts are done only one step ahead it is not introduced autocorrelation across errors. In this case a consistent estimate of $2 \pi f(0)$ will be the sample variance of square errors difference (see Campbell et al (1997), page 535). Table IX displays the Diebold and Mariano test results. The rank ordering of the models based MSE $_{C}$ values and the $S_{1}$ statistic for the significance of its differences is the following

$$
\text { SVASICEK }=\text { SCKLS }=\text { SGENERAL }=\text { SCIR }<\text { SBS }<\text { VASICEK }=\text { CKLS }=\text { GENERAL } \leq \text { CIR }<\text { BS }
$$

where ' $=$ ' means that $\mathrm{MSE}_{\mathrm{C}}$ difference is not statistically significant and ' $<$ ' means than left models $\mathrm{MSE}_{\mathrm{C}}$ is significantly lower than right models $\mathrm{MSE}_{\mathrm{C}}$ at $95 \%$ confidence level. The symbol ' $\leq$ ' means that at $90 \%$ confidence level there is a ' $<$ ' but at $95 \%$ confidence there is a '='. Now we can make more precise the intuitive lecture of Table VIII: seasonal models set improve forecast precision compared with not seasonal models set. That is, including a seasonal trend is important as seasonal models overperform all not seasonal models. Furthermore, into each of these sets there are no differences across models except for the BS model which is clearly the worst one. The rank ordering of the models when comparing $\mathrm{MSE}_{\mathrm{V}}$ is

GENERAL $=$ SGENERAL $<$ CKLS $\leq$ SCKLS $<$ VASICEK $\leq$ SVASICEK $<$ SCIR $<$ CIR $<$ SBS $<$ BS

\footnotetext{
${ }^{7}$ When $\mathrm{S}_{1}<-1.96$ model "i" has a MSE significantly lower than model " $\mathrm{j}$ ” at 95\% confidence level.

When $\mathrm{S}_{1}>1.96$ model “j” has a MSE significantly lower than model "i” at 95\% confidence level.
} 
where symbols have the same meaning than above. From this statistical relationship we find: (1) that the introduction of a seasonal trend does not improve the volatility forecasting performance except for CIR and BS models, (2) models with more structure in modeling conditional volatility, SGENERAL and GENERAL with the GARCH structure followed by SCLS and CKLS with free $\gamma$, are the best ones. But SCIR, CIR, SBS and BS which have constrained values for $\gamma$ are worse than SVASICEK and VASICEK which have a constant volatility, (3) the $\mathrm{MSE}_{\mathrm{V}}$ values allows an identical ranking across models to the one obtained from log-likelihood function values into the sets of seasonal and not seasonal models. As a conclusion we can say that the election of volatility structure determines eventually the model selection. Furthermore, by intersection between $\mathrm{MSE}_{\mathrm{C}}$ and $\mathrm{MSE}_{\mathrm{V}}$ rankings the SGENERAL model is the best performing model.

Table VIII: Performance Measures

This table exhibits the Mean Square Error for the forecasted conditional mean change $\left(\mathrm{MSE}_{\mathrm{C}}\right)$ and the forecasted conditional variance $\left(\mathrm{MSE}_{\mathrm{V}}\right)$. Unexpected changes are measured by $\left(\mathrm{I}_{\mathrm{t}}-\mathrm{I}_{\mathrm{t}-1}\right)$ and conditional volatility by $\left(\mathrm{I}_{\mathrm{t}}-\mathrm{I}_{\mathrm{t}-1}\right)^{2}$. MSE is defined as follows

$$
\operatorname{MSE}=\frac{1}{\mathrm{~N}} \sum_{\mathrm{i}=1}^{\mathrm{N}}\left(\mathrm{y}_{\mathrm{i}}-\hat{y}_{\mathrm{i}}\right)^{2}
$$

where $y_{i}$ and $\hat{y}_{i}$ denote the actual and forecasted values of $\left(I_{t}-I_{t-1}\right)$ for $\operatorname{MSE}_{C}$ and $\left(I_{t}-I_{t-1}\right)^{2}$ for $\mathrm{MSE}_{\mathrm{V}}$.

\begin{tabular}{llcc}
\hline & MODELS & MSE $_{\mathrm{C}}$ & MSE $_{\mathrm{V}}$ \\
\hline Seasonality & (1) SGENERAL & 1.5475 & 8.3753 \\
& (2) SCKLS & 1.5475 & 8.4371 \\
& (3) SVASICEK & 1.5472 & 8.5398 \\
& (4) SCIR(85) & 1.5486 & 9.5669 \\
& (5) SBS & 1.5592 & 19.6233 \\
\hline No seasonality & (6) GENERAL & 1.6495 & 8.3624 \\
& (7) CKLS & 1.6495 & 8.4227 \\
& (8) VASICEK & 1.6492 & 8.5252 \\
& (9) CIR(85) & 1.6533 & 9.7431 \\
& (10) BS & 1.6949 & 21.1335 \\
\hline
\end{tabular}




\section{Table IX: Test of equal accuracy of two competing forecasts}

This table displays Diebold and Mariano (1995) statistic $S_{1}$ comparing the forecasting ability of two competing models (see equation (4) in text). Diebold and Mariano show that $S_{1}$ is asymptotically distributed $N(0,1)$. In these case we adapte Diebold and Mariano statistic to compare the Mean Square Error of two alternative models. When $S_{1}<-1.96$ the heading column model has a MSE significantly lower than the heading row model and vice versa. The critical values are $+/-1.64$ and $+/-1.96$ for a confidence level of $90 \%$ and $95 \%$ respectively. $(*$ ) and (**) means $\mathrm{S}_{1}$ significant at $5 \%$ and $10 \%$ significance level, respectively.

\begin{tabular}{|c|c|c|c|c|c|c|c|c|c|c|}
\hline \multicolumn{11}{|c|}{ TEST OF EQUAL ACCURACY FORECASTING CHANGES IN TEMPERATURE } \\
\hline MODELS & SGENERAL & SCKLS & SVASICEK & $\operatorname{SCIR}(85)$ & SBS & GENERAL & CKLS & VASICEK & $\mathrm{CIR}(85)$ & $\mathrm{BS}$ \\
\hline \multicolumn{11}{|c|}{ SGENERAL } \\
\hline SCKLS & 0.12 & & & & & & & & & \\
\hline SVASICEK & 0.64 & 0.55 & & & & & & & & \\
\hline $\operatorname{SCIR}(85)$ & -0.79 & -0.82 & -1.49 & & & & & & & \\
\hline SBS & $-4.37 *$ & $-4.51 *$ & $-5.02 *$ & $-5.34 *$ & & & & & & \\
\hline GENERAL & $-13.23^{*}$ & $-12.98 *$ & $-13.14 *$ & $-13.04 *$ & $-11.33^{*}$ & & & & & \\
\hline CKLS & $-13.24 *$ & $-12.99 *$ & $-13.15^{*}$ & $-13.05^{*}$ & $-11.38^{*}$ & 0.04 & & & & \\
\hline VASICEK & $-13.19 *$ & $-12.93^{*}$ & $-13.13^{*}$ & $-13.10^{*}$ & $-11.41 *$ & 0.56 & 0.53 & & & \\
\hline CIR(85) & $-13.38^{*}$ & $-13.10^{*}$ & $-13.41^{*}$ & $-13.65^{*}$ & $-12.08^{*}$ & $-1.84 * *$ & $-1.85 * *$ & $-2.54 *$ & & \\
\hline $\mathrm{BS}$ & $-16.03^{*}$ & $-15.77^{*}$ & $-16.25^{*}$ & $-17.01^{*}$ & $-16.49 *$ & $-8.39 *$ & $-8.44 *$ & $-9.16^{*}$ & $-11.76^{*}$ & \\
\hline \multicolumn{11}{|c|}{ TEST OF EQUAL ACCURACY FORECASTING TEMPERATURE VOLATILITY } \\
\hline SGENERAL & & & & & & & & & & \\
\hline SCKLS & $-2.57 *$ & & & & & & & & & \\
\hline SVASICEK & $-4.71 *$ & $-3.91 *$ & & & & & & & & \\
\hline $\operatorname{SCIR}(85)$ & $-18.11 *$ & $-18.14 *$ & $-24.56^{*}$ & & & & & & & \\
\hline SBS & $-51.91 *$ & $-51.65^{*}$ & $-53.44 *$ & $-57.00 *$ & & & & & & \\
\hline GENERAL & 1.10 & 2.60 & $4.55^{*}$ & $17.77 *$ & $52.17^{*}$ & & & & & \\
\hline CKLS & $-2.01 *$ & $1.74 * *$ & $4.08 *$ & $18.25^{*}$ & $52.07 *$ & $-2.23^{*}$ & & & & \\
\hline VASICEK & $-4.51 *$ & $-3.51 *$ & $1.75 * *$ & $25.41 *$ & $54.09 *$ & $-4.45^{*}$ & $-3.89 *$ & & & \\
\hline $\operatorname{CIR}(85)$ & $-20.05^{*}$ & $-20.01 *$ & $-26.07 *$ & $-19.16^{*}$ & $57.73^{*}$ & $-19.82 *$ & $-20.27 *$ & $-27.28^{*}$ & & \\
\hline $\mathrm{BS}$ & $-53.74 *$ & $-53.45^{*}$ & $-55.00 *$ & $-58.19 *$ & $-63.79 *$ & $-54.00 *$ & $-53.87 *$ & $-55.61 *$ & $-58.87 *$ & \\
\hline
\end{tabular}




\section{Simulation}

In this section, we will use the estimated models to simulate derivatives payoffs and obtain some evidence for price derivatives on temperature. As we have already discussed, temperature is non-tradable, and there is no currently available derivative for Spanish temperature so the temperature market price of risk is impossible to obtain. This fact is very important because the traditional arbitrage-free methodology cannot be directly applied. However, we can simulate real probability results of variable temperature and this could be useful for agents when they are taking positions in assets, or economic activities, that are closely related to temperature. These agents could obtain expected values either with real probabilities coming from sample data, or pseudo-real probabilities obtained through simulation with previously estimated stochastic models. With this information, investors can bet on those assets that are expected to show better behaviour, although this is quite far from being an asset valuation.

We have generated two kinds of simulated data. Both are useful when dealing with temperature risk, but they have a different meaning. Firstly, we will calculate the simulated probabilities of temperature. We have simulated a series with 10712 daily values in the SGENERAL and SCKLS models (corresponding to 29 years). Figure 5 shows the histograms of the sample and the simulated models. The simulated probabilities and the sample probabilities are notably close, the models being able to reproduce the two modes shown by the original sample. These results give us confidence in our estimated models.

Figure 5: Histogram for the STI, Simulated SGENERAL Model and Simulated SCKLS (10712 observations and simulated data series).

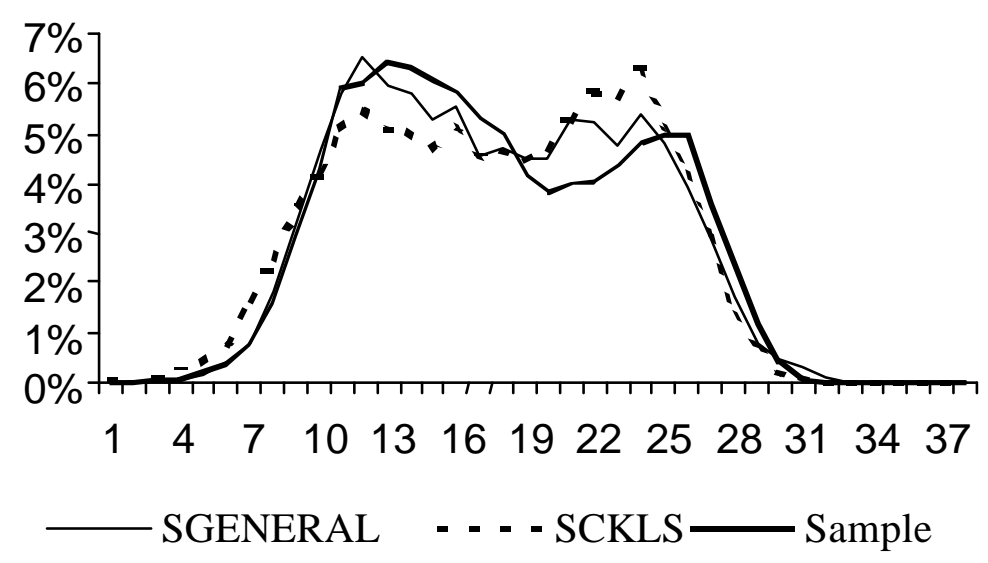


The second kind of simulations refer to a very common underlying variable on weather derivatives: the heating degree-days (HDD), defined as max (18 - STI, 0), and the cooling degree-days (CDD), defined as $\max \left(\mathrm{STI}-18^{\circ}, 0\right)$. These functions determine the intensity and duration of coldness and heat, respectively, by measuring the departure of air temperature from a reference value at which electricity is consumed neither for heating nor cooling the environment. As can be deduced from figure 1, a good reference for Spain is around $18^{\circ} \mathrm{C}$, where the minimum consumption is observed (Valor et al., 2000). Table $\mathrm{X}$ displays simulated results for all the models estimated in Table VII. We have generated 10000 times the temperatures for a whole year (365 days). In every simulated year we sum the total HDD and CDD. Then we compute the average and its standard deviation for the 10000 years generated. We can apply the central limit theorem under the hypothesis that the yearly generated CDD, or HDD, sums are random variables identically and independently distributed by using normal distribution to calculate mean standard deviation values and so confidence intervals can be computed. We also report results for sample data for comparison purposes.

\section{Table X: Simulating Average Heating and Cooling Degree-days}

This table displays simulated results for all the models shown in Table VII. Average values for Heating Degree-Days (HDD), defined as $\max \left(18^{\circ}\right.$ - STI, 0), and Cooling Degree-Days (CDD), defined as $\max \left(\mathrm{STI}-18^{\circ}, 0\right)$, are displayed after simulating 10000 times the temperatures for a whole year (365 days) in each model. In each simulated year, we sum the total HDD and CDD.

Then we compute the average and its standard deviation for the 10000 years generated.

\begin{tabular}{|c|c|c|c|c|c|}
\hline & & AVERAGE & STAND. DEV. & AVERAGE & STAND. DEV. \\
\hline & & \multicolumn{2}{|c|}{ HDD } & \multicolumn{2}{|c|}{$\mathrm{CDD}$} \\
\hline \multirow[t]{5}{*}{ Seasonality } & (1) SGENERAL & 1201.60 & 1.05 & 647.38 & 1.11 \\
\hline & (2) SCKLS & 1126.69 & 2.65 & 596.03 & 2.02 \\
\hline & (3) SVASICEK & 1193.74 & 1.21 & 640.42 & 1.04 \\
\hline & (4) SCIR(85) & 1183.95 & 1.16 & 629.73 & 1.31 \\
\hline & (5) SBS & 1241.68 & 1.28 & 649.72 & 1.92 \\
\hline \multirow[t]{5}{*}{ No seasonality } & (6) GENERAL & 1115.22 & 6.56 & 546.52 & 3.79 \\
\hline & (7) CKLS & 1197.01 & 7.31 & 563.80 & 3.85 \\
\hline & (8) VASICEK & 1119.46 & 5.83 & 585.03 & 4.06 \\
\hline & (9) $\mathrm{CIR}(85)$ & 1120.87 & 4.17 & 550.09 & 3.84 \\
\hline & (10) BS & 1375.76 & 3.18 & 428.06 & 3.16 \\
\hline \multicolumn{2}{|c|}{ SAMPLE VALUES (29 years) } & 1289.32 & 169.83 & 687.02 & 213.09 \\
\hline
\end{tabular}


From Table $\mathrm{X}$ we can argue that for any considered model we obtain reasonable results, as they provide simulated average HDD and CDD similar to the sample average. So, we can trust on these estimated models. Furthermore, the standard deviations show that the computed average has little dispersion. Comparing models with, and without seasonality, gives an interesting result. Models with seasonality obtain smaller standard dispersion values, and so it seems that the introduction of a seasonal trend increases the stability of the variables used as reference in weather derivatives.

\section{Conclusions}

The aim of this paper has been to model air temperature behaviour using the techniques applied when modelling short-term interest rates. The variable temperature is a population-weighted average of the temperatures measured at four Spanish weather stations. A preliminary analysis of the temperature series reveals that financial models could be adapted to explain the behaviour of this weather variable.

The starting point of the study has been the different models described in the works of Bali (1999) and Chan et al. (1992). We have added a new term to account for the strong seasonal pattern shown by the temperature variable, following Pilipovic (1998). The use of mean reversion (including seasonality), GARCH structures, and relationships between volatility and temperature levels for modelling, has been stressed. We have proposed a general model that incorporates all these features, and which has been estimated together with other models previously proposed (BS, CIR(85), VASICEK, and CKLS), both with and without the seasonality term (10 models in total). The performance of the models is significantly improved by the presence of a structure including mean reversion to a seasonal trend and conditional volatility. The model we propose overperforms in explicative power and forecasting ability to the most common single factor stochastic models existing in the literature.

Best performing models have been used to obtain the average and standard deviation values for the HDD and CDD. The average values coincide with the sample means, and the models including seasonality are more stable (since they show less standard deviation values in the HDD and CDD simulations). 
Three facts are remarkable in the overall analysis. Firstly, a reliable model must contain a mean reversion to the seasonal trend. Secondly, there is an autoregressive behaviour in temperature conditional volatility. And lastly, volatility has low sensitivity to the temperature level, and both are inversely related. These characteristics should be considered in selecting a model to value weather derivatives. 


\section{References}

Bali, T.G. (1999), 'An empirical comparison of continuous time models of the short term interest rate', The Journal of Futures Markets, 7, pp. 777-797.

Berndt, E.K., Hall, B.H., Hall R.E. and J.A. Hausman (1974), 'Estimation and Inference in Nonlinear Structural Models', Annals of Economic and Social Measurement, 3/4, pp. 653-665.

Bollerslev, T. (1986), 'Generalized Autorregresive Conditional Heteroskedasticity', Journal of Econometrics, 31, pp. 307-327.

Brennan, M.J. and Schwartz, E. (1982), 'An equilibrium model of bond pricing and a test of market efficiency', Journal of Financial and Quantitative Analysis, 17, pp. 75-100.

Brenner,J.R., Harjes, R.H., and Kroner, K.F. (1996), 'Another Look at Models of Short-Term Interest Rate', Journal of Financial and Quantitative Analysis, 31, 1

Campbell, J.Y., Lo, A.W. and MacKinlay A.C. (1997), The Econometrics of Financial Markets, Princeton University Press, Princeton, New Jersey.

Cox, J.C., Ingersoll, J. and Ross, S. (1985), 'A theory of the term structure of interest rates', Econometrica, 53, pp. 385-407.

Chan, K., Karoly, A., Longstaff, F. and Sanders, A (1992), 'An empirical comparison of alternative models of the short term interest rate', Journal of Finance, 3, pp. 12091226.

Diebold, F.X. and Mariano, R. (1995), 'Comparing Predictive Accuracy', Journal of Business and Economic Statistics, 13, pp. 253-263.

Dischel, B. (1998), 'Black-Scholes won't do', Risk, October, pp. 8-9.

Engle, R. (1982), 'Autoregressive Conditional Heteroskedasticity with Estimates of the Variance of U.K. Inflation', Econometrica, 50, pp. 987-1008.

Engle, R.F., Mustafa, C. and Rice, J. (1992), 'Modelling peak electricity demand', Journal of Forecasting, 11, pp. 241-251.

Henley, A. and Peirson, J. (1998), 'Residential energy demand and the interaction of price and temperature: British experimental evidence', Energy Economics, 20, pp. 157-171. 
Li, X and Sailor, D.J (1995), 'Electricity use sensitivity to climate and climate change', World Resource Review, 3, pp. 334-346.

Moreno, M. and Peña, J.I. (1996), 'On the term structure of interbank interest rates: jumpdiffusion processes and option pricing', Forecasting Financial Markets: Exchange Rates, Interest Rates and Asset Management, 7, pp. 159-180.

Pardo, A., Meneu V. and Valor, E. (2000), 'Temperature and seasonality influences on Spanish electricity load', Energy Economics (submitted).

Peirson J. and Henley, A. (1994), 'Electricity load and temperature. Issues in dynamic specification' Energy Economics, 16, 235-243.

Pilipovic, D.(1998), Energy Risk, McGraw-Hill, New York.

Pirrong, C. and Jermakyan, M. (1999), 'Valuing power and weather derivatives on a mesh using finite difference methods', Energy Modelling and the Management of Uncertainty, Risk Books, London, pp. 59-69.

Sailor, D.J. and Muñoz, J.R. (1997), 'Sensitivity of electricity and natural gas consumption to climate in the USA - methodology and results for eight states', Energy, 22, pp. 987998.

Valor, E., Meneu, V. and Caselles, V. (2000), 'Daily air temperature and electricity load in Spain', Journal of Applied Meteorology (submitted).

Vasicek, O. (1977), 'An equilibrium characterization of the term structure', Journal of Financial Economics, 5, pp. 177-188. 